\title{
COMPARATIVE ANALYSIS BETWEEN THE FUNDAMENTAL AND TECHNICAL ANALYSIS OF STOCKS
}

\author{
Prof. Nada Petrusheva Ph.D \\ FON University - Skopje, Republic of Macedonia \\ natka.petrusheva@fon.edu.mk \\ Igor Jordanoski, MSc \\ FON University - Skopje, Republic of Macedonia \\ igor.jordanoski@fon.mk
}

\begin{abstract}
In the world of investing and trading, in order to have a definite advantage and constantly create profit, you need to have a strategic approach. Generally speaking, the two main schools of thought and strategies in financial markets are fundamental and technical analysis. Fundamental and technical analysis differ in several aspects, such as the way of functioning and execution, the time horizon used, the tools used and their objective. These differences lead to certain advantages and disadvantages of each of the analyses. Fundamental and technical analysis are also a subject of critical reviews by the academic and scientific community and many of these reviews concern the methods of their application, i.e. the possibility of combining the two analyses and using them complementarily to fully utilize their strengths and advantages.
\end{abstract}

Key words: fundamental analysis, technical analysis, investing, value investing, trading

\section{Introduction}

Fundamental analysis is used to calculate the true intrinsic value of a share and to find opportunities where that share value differs from its current market price. In order to do this, fundamental analysis looks at economic factors, known as fundamentals. These fundamentals are mainly found in the company's financial reports, as well as reports about various macro-economic indicators and variables. Fundamental analysis is based on the assumption that there is a time delay in the affecting of share prices by these fundamentals. Technical analysis is used to predict the future market price of a share using statistics on the past performance of that share. Technical analysis takes into account the past changes in the price of a share and attempts to predict its future price movements and changes. Technical analysis is based on the assumption that patterns in stock price movements repeat themselves and can determine the best times for you to buy and sell.

\section{Differences between the fundamental and technical analysis}

\section{- The way of working}

Fundamental analysis attempts to calculate the future value of a share through various economic variables, known as fundamentals. The analysis consists of studying the economy as a whole, the industry in which the company operates and the company itself. The basic premise of this analysis is that in the short term, the share price does not correspond to its value, but in the long run it will correct itself. You can make a profit by buying shares at a lower price than their true value or by selling shares at a higher price that their actual value.

The main task of fundamental analysis is to determine the true value of a share. Whoever performs the analysis should consider the overall performance of the company and its financial statements, including all the latest news about the company. Based on all that, he should conclude whether the market properly evaluated all the information into the share price. The investor needs to consider all parts of financial statements, including profits, assets, revenues and expenses, make a comparative analysis by year, make a comparative analysis by certain industry standards, notice certain trends in their behavior and based on all that, make proper valuation of the shares. After all, stock 
prices are inevitably dependent on all these numbers and only through their analysis, the investor can understand how prices react to certain changes in the company's financial performance.

The best worldwide example of an investor who applied fundamental analysis is the renowned Warren Buffett. ${ }^{1} \mathrm{He}$ is also known as the Oracle of Omaha because he is from Ohama, Nebraska. He used value investing, i.e. invested in shares he thought were undervalued, and waited, sometimes even for a long periods of time, for the prices to increase to their expected level.

Technical analysis attempts to predict the share price in the future. It does not deal with all the economic factors that may affect it, but only with the share price's movements. Additionally, for the technical analyst it does not matter what is the real value of the share, but only what are the price patterns created by supply and demand and what insights we can get from them. The purpose of technical analysis is to forecast the stock price in order to establish favorable moments for buying and selling stocks.

Technical analysis is based on the premise that all the important fundamental factors are already reflected in the share price. Accordingly, it focuses only on the share price and trading volume, which are measured and presented at various tables and graphs. By analyzing these graphs, the investor can obtain information about certain trend formations and regularities in the price movement, the trading volume and their inter dependence. One of the more popular charting tools is the candlestick chart, named because it resembles a candle. The figure for each trading period is plotted to show the high and low prices for the period, along with the opening and closing prices. The most common types of price patterns are:"head and shoulders", which shows that after its formation, the price will start moving in the opposite direction of the previous trend, "cup and handle", a pattern

\footnotetext{
${ }^{1}$ Kumar, R. (2014): How technical and fundamental analysis can help your trading decisions, RKSV
}

that shows that there is a growing trend, which will continue after a small pause and "double tops and bottoms", a pattern that suggests a changing trend. Technical analysis also uses moving averages. They level the short-term price fluctuations and also help in the detection of ascending and descending trends. Levels of support and resistance are another aspect that can be analyzed by moving averages. For example, if a share is in a downward trend, when it reaches the level of support of a long-term moving average, it will probably change its direction. $^{2}$

These differences are due to the basic principle in which fundamental analysts believe, which is that the shares are not correctly valued by the market at any given moment. Technical analysts consider all external factors instantly reflected into the share price, as opposed to fundamental analysts, who believe that it takes some time for it to happen. Therefore, there is an opportunity to make profits in the time when the price has still not reflected every available company-related information in it. The nature and methods of the technical analysis make it useful for short term trading and therefore, it is used mostly for trading purposes, while fundamental analysis, on the other hand, is mainly used for investments.

\section{- Time horizon}

Fundamental analysis uses longer periods when analyzing stocks than technical analysis. Technical analysis uses relatively short periods, that may be days, weeks or months, while fundamental analysis uses periods of several years. ${ }^{3}$

Therefore, that implies that the fundamental analysis is used by investors who are trying to pick stocks whose value will increase in the future, over several years. They believe that if they have chosen the correct stocks, their price will eventually rise, even if it takes several years for that to happen. In

\footnotetext{
2 "Fundamental analysis versus technical analysis", from www.diffen.com

${ }^{3}$ B\&R Beurs, www.bnrbeurs.nl
} 
contrast, the technicians are trying to find stocks that they can trade in the short term, i.e. stocks whose prices will experience significant changes in the coming days or weeks.

The different investment styles implemented by investors who use fundamental and those who use technical analysis lead to different time frames in their analyses. As we know, the fundamental analyst estimates the real value of the share, but that value will become its market price after a certain time has passed. It is this way of investing that is known as value investing. If the market reflects all share-related changes momentarily to its price, then the value investing and the fundamental analysis itself would not be possible. In addition, the data used by fundamental analysts is not published daily as is the case with the data on price movements and trading volume, but is published on a quarterly or annual basis. Sometimes, financial statements are published only annually, while the price data is available almost instantly.

\section{- Charts vs. Financial statements}

Fundamental analysts have the financial statements as the main source of information, while technical analysts use charts with price movements as the almost only source of data. The fundamental analyst estimates the intrinsic value of the stock by analyzing the income statements, balance sheets and the statements of cash flow. In this approach, the investment decision logic is simple - if the stock trades at a price lower than its estimated intrinsic value, than it's a good investment. Fundamental analysts use however more complex information in their analysis, not only the data found in the financial statements. On the other hand, technical analysts believe that all you need to know about a stock can be found within the stock price's charts. ${ }^{4}$

\section{- Trading vs. Investing}

The time difference between fundamental and technical analysis is seen not only in their short-term or long-term approach, but also in their purpose. In general, the purpose of the technical analysis is trading, and the goal of fundamental analysis is investment. Fundamental analysis is primarily used by investors who buy and hold stocks for a period of time, while technical analysis is most frequently used by traders looking to make short-term profits. Investors buy certain stocks because they believe that their value will increase in the future, while traders buy certain stocks because they think they will be able to sell them at a higher price in a relatively short period of time. Sometimes, this difference may not be so clear, but there is certainly a distinct approach between these philosophies. They certainly seem similar and generally use the same idea and concept, but they are essentially different schools of thought. ${ }^{5}$

\section{Advantages and disadvantages of the fundamental and technical analysis of stocks}

The first advantage of fundamental analysis is that it examines real economic and market factors in assessing the value of stocks. With fundamental analysis, you seek to understand trends in the economy, business sectors and companies to determine if stocks are priced fairly given the prevailing economic conditions. You begin your analysis by examining the economic outlook to determine which industry groups are likely to benefit. Understanding the group is as important as picking the industry leaders - the top firms in a stagnant or declining industry are not going to be wise picks. The analysis concludes with studying the leaders in the rising industries, looking at key statistics, management and the business plans.

\footnotetext{
${ }^{5}$ Warneryd, K.E. (2002): Stock market psychology: How people value and trade stocks, E. Elgar Pub
}

\footnotetext{
${ }^{4}$ B\&R Beurs, www.bnrbeurs.nl 
The second advantage of fundamental analysis is the fact that stock prices are determined by the companies performances and their prospects to make a profit. Therefore, if you make accurate forecasts and predictions about future profits, it is likely that the valuation of the market prices of shares will be relatively accurate.

The third advantage of fundamental analysis is the economic logic and viability of the investment criterion, which is that a share is a good investment choice when its market value is lower than its true intrinsic value, i.e. when it is undervalued and vice versa, the share is not recommended for buying when its market value is higher than its true intrinsic value.

The main weakness of fundamental analysis is that it is time-consuming. You cannot quickly locate and absorb the information you need to make thoughtful stock picks. Your judgments are subjective, as is your definition of fair value. You may need to use different criteria to evaluate different industry groups, which will also be timeconsuming.

The second drawback of the fundamental analysis is in relation to the efficient market hypothesis. Since all information about stocks is public knowledge - barring illegal insider information - stock prices reflect that knowledge. If stock prices are based on all known information, then they can neither be undervalued nor overvalued. But information flows are imperfect, and if your exercise due diligence, you will be more successful than those who do not. ${ }^{6}$

A major advantage of technical analysis is its simple logic and application. It is seen in the fact that it ignores all economic, market, technological and any other factors that may have an impact on the company and the industry and only focuses on the data on prices and the volume traded to estimate future prices. After the emergence of a particular pattern in the price movement of the stock, the technical analyst assumes that this pattern will be repeated in the future

\footnotetext{
${ }^{6}$ Knapp, S.P.V. (2008): Sensible stock investing: How to pick, value and manage stocks, iUniverse
}

and he makes his trading decisions in accordance with this assumption. As we have said before, the main goal of technical analysis is to find specific price trends in the market. A typical example would be if the analyst notices that whenever a particular stock declined $4-5 \%$, in the following period, it had experienced sharp upward movement. This knowledge leads the analyst to a trading signal -when the price falls by $4-5 \%$, he can now buy the stock and make a profit from the expected price increase. Traders and technical analysts are constantly looking for signals of these kind, which can then be used to achieve short-term profits.

The second advantage of technical analysis lies in the fact that there are a number of computer tools and programs that facilitate the analysis. Unlike fundamental analysis, where it is not simple to investigate certain factors such as the potential for future growth of the company and the industry and branch situation, in technical analysis, by simply entering the necessary parameters in the corresponding computer program, you can get certain investment signals. Of course, financial and investment understanding and skills are required to interpret these signals and take appropriate actions.

The third advantage of technical analysis is that it excludes the subjective aspects to certain companies, such as the analyst's personal expectations. The final decision is based solely on what the results of the graphs suggest. Furthermore, the technical analysis helps making time decisions, i.e. what is the right time to buy or sell certain shares.

The main drawback of the technical analysis is that it has no academic or scientific confirmation and it can't be validated by any rational arguments. Critics of technical analysis compare it to reading tea leaves. There is nothing, they say, about a chart formation that necessarily makes a stock move in a predictable manner. On the other hand, if enough followers believe in the predictive power of the chart, they will 
engage in the buying and selling activity that will make the prediction come true.

\section{Criticism toward the fundamental and technical analysis}

Some critics see technical analysis as a form of black magic. In fact, technical analysis has only recently begun to enjoy some mainstream credibility. ${ }^{7}$ Most of the criticism towards technical analysis derives from the economic theory, i.e. the efficient market hypothesis. According to this hypothesis, the current market price of a particular share is always the accurate price because it has already calculated in it all the information available that may have influenced the share, hence, questioning any analysis that claims to have found undervalued stocks in the market. There are three levels of this theory. The weak-form efficiency assumes that all historic price movements are already reflected in the share price, hence the analysis of such price movements can't lead to predictions for the future price patterns. However, it remains possible that through fundamental analysis you can find certain fundamental factors, that could influence the future share price. The semi-strong efficiency reduces the contribution that fundamental analysis can have in selecting stocks for investing. The strong form efficiency states that all the existing market information in connection with the share and with the company is already taken into account and therefore, neither technical nor fundamental analysis can help you find and detect favorable investment opportunities. ${ }^{8}$ Many academics believe in some version of the efficient market hypothesis, therefore, questioning the credibility of both the technical and fundamental analysis.

\footnotetext{
7 Schabacker, R.W., Mack, D. (2005): Technical analysis and stock market profits: A course in forecasting, Harriman House

${ }^{8}$ PCM Brokers, www.pcmbrokers.com 30
}

\section{Combined use of the fundamental and technical analysis}

Technical and fundamental analysis are seen as total opposites in the world of investments. However, many investors and traders have managed to combine them and achieve successful results. Investors who apply mainly fundamental analysis, can use technical analysis to determine the exact time when to make a transaction, whether it's buying or selling. Since technical analysis is primarily a market timing tool, it can be implemented effectively in conjunction with fundamental analysis. The proper assessment of the time to enter into the investment opportunity can sometimes be more important and the investment itself. Therefore, the best advice would be to study the fundamental factors, make the investment decision and use the technical analysis to determine the time of purchase or sale.

On the other hand, investors who use mainly technical analysis, in some cases can benefit from fundamental analysis. If a technical analyst detects certain price pattern and determine that some particular stock is a good investment, he can further confirm his assessment by analyzing some important fundamentals of the company, which can provide valuable information about its financial position and its capacity. This suggests that the fundamental and technical analysis differ between each other, but they are not necessarily mutually contradictory. In general, the proponents of both technical and fundamental analysis are not big advocates of the idea of combining them. However, it is undeniable that there are certain advantages in combining them or at least having a deeper knowledge of both types of investment strategies, since technical and fundamental analysis are the most important and the most powerful tools in the realm of finance and investing.

\section{Conclusion}

We have seen that the fundamental and technical analysis are different in many aspects, starting from the assumptions on 
which they are based, to the methods used and the function they have. These differences show that the fundamental and technical analysis are essentially different strategies for making investment decisions. However, the observed differences don't necessarily indicate that fundamental and technical analysis lead to different investment decisions. In fact, both analyses have their advantages and disadvantages that can be combined to give optimum results.

\section{References}

[1] Knapp,S.P.V. (2008): Sensible stock investing: How to pick, value and manage stocks, iUniverse

[2] Kumar,R. (2014): How technical and fundamental analysis can help your trading decisions, RKSV

[3] Schabacker,R.W., Mack, D. (2005):Technical analysis and stock market profits: A course in forecasting, Harriman House

[4] Warneryd,K.E. (2002): Stock market psychology: How people value and trade stocks, Edward Elgar Pub

[5] Fundamental analysis versus technical analysis, from www.diffen.com

[6] B\&R Beurs: www.bnrbeurs.nl

[7] PCM Brokers: www.pcmbrokers.com 